\title{
SURVIVAL OUTCOMES IN EARLY GLOTTIC CARCINOMA: A SINGLE INSTITUTION EXPERIENCE
}

\author{
Muhammad Atif Munawar, Kamran Saeed, Tabinda Sadaf, Irfan Haider, Arif Jamshed \\ Department of Radiation Oncology, Shaukat Khanum Memorial Cancer Hospital and Research Centre, Lahore, \\ Pakistan
}

Received: 2 June 2015 / Accepted: 20 December 2016

\begin{abstract}
Purpose: Laryngeal cancers are amongst the most common cancers affecting head and neck region. In this study, we analyse the overall survival (OS) following hypofractionated radiotherapy (RT) in early-stage glottic carcinoma treated at Shaukat Khanum Memorial Cancer Hospital and Research Centre, Lahore.

Methods: Between October 2003 and June 2009, 87 patients with early-stage glottic carcinoma were treated with hypofractionated RT. All patients were included in the study. The ratio of male: female is $94 \%: 6 \%$. Mean age was 62 years (range $31-83$ years). $66 \%$ of the patients were smokers. AJCC stage was T1a in 76\%, T1b 20\% and T2 in 4\% of the patients. Histological distribution was; squamous cell carcinoma $97 \%$, verrucous carcinoma $2 \%$ and squamous cell spindle variant $1 \%$. Median follow-up time was 59 months (range 4-122 months). RT dose was 55 Gy in 20 fractions over a period of 4 weeks. Median RT treatment time was 28 days (range 23-35 days). Patients that lost to follow-up were contacted through telephone.
\end{abstract}

Results: The 10-year OS was $83 \%$. Patterns of failure was 7 local and 1 distant while 1 patient had persistent disease. 15 patients were dead at the time of study. Cause of death; 13 patients died due to Ischemic heart disease and 2 due to primary disease.

Conclusion: Hypofractionated RT 55 Gy in 20 fractions seems to achieve good OS while offering potential for optimizing resources usage.

Key words: Glottic carcinoma, hypofractionated, overall survival, radiotherapy

\section{Introduction}

Larynx or voice box is divided into three regions, supraglottis, glottis and subglottis. Amongst them, glottic cancers comprise $60-65 \% \cdot{ }^{[1]}$ Main histology is the squamous cell carcinoma and almost $40 \%$ of the patients have Stages III and IV disease at the time of presentation..$^{[2]}$ Patients with early squamous cell carcinoma of the laryngeal glottis are generally considered to have good prognosis. ${ }^{[3,4]}$ The aims of treatment for early glottis cancer are cure, laryngeal voice preservation, optimal voice quality with minimal morbidity, expense and inconvenience ${ }^{[5]}$ Both treatment modalities including

Correspondence: Muhammad Atif Munawar, Department of

Radiation Oncology, Shaukat Khanum Memorial Cancer

Hospital and Research Centre, Lahore, Pakistan.

Email: dratifmunawar@gmail.com surgery and radiation therapy are fairly successful in the management of early glottis cancers; the treatment of choice remains controversial as the evidence for most decisions is derived from non-randomised studies. ${ }^{[6]}$ Radiation therapy has comparable cure rates for selected $\mathrm{T} 1$ and T2 early-stage glottis cancers with laser excision, cordectomy and hemilaryngectomy. Radiation therapy is preferred over surgery due to its less selection criteria, good quality of voice and comparable local control and survival rates. ${ }^{[3]}$ Local control rates have ranged from $80 \%$ to $95 \%$ for $\mathrm{T} 1$ and from $50 \%$ to $80 \%$ for T2 early glottic cancers treated with radiotherapy (RT). There is a range of radiation fractionation policies for the treatment of early laryngeal cancer worldwide. While most centres have adopted conventional 2 Gy fractionation for 6-7 weeks, others use hypofractionated regimens with shorter overall time. ${ }^{[7-9]}$ 
RESEARCH ARTICLE

The traditional approach to the treatment of Stage I vocal cord cancer has been to deliver 66-70 Gy in 2 Gy daily fractions. A Japanese randomised trial compared hypofractionated RT at 2.25 Gy daily with 56.25 Gy for 'minimal' $\mathrm{T} 1$ and between 63 Gy for larger T1 tumours with 60-66 Gy in 2-Gy fractions. Local control was superior with hypofractionation, and toxicity was reported as extremely low in both arms, leading to widespread adoption of the hypofractionated regimen.

The use of hypofractionation to minimise potential for tumour repopulation during RT is particularly important for early larynx in view of small field sizes, potentially allowing larger doses per fraction without excessive late morbidity. ${ }^{[9]}$ There are only limited published data documenting the efficacy of the more hypofractionated schedules. Importantly, these are little data available to support the use of similar schedules for the treatment of $\mathrm{T} 2$ glottic carcinoma, with the two main series reporting the use of hypofractionated schedules with fraction sizes $>2.5$ Gy included only T1 disease. ${ }^{[11,12]}$

A study published in 2011 in International Journal of Head and Neck Surgery showed 5-year overall survival (OS) of $86 \% .{ }^{[13]}$ Those patients were followed for another 5 years, and here, we report our 10-year experience of treating $\mathrm{T} 1$ and $\mathrm{T} 2$ glottic carcinoma with 55 Gy in 20 fractions over a period of 4 weeks.

\section{Methods}

The time duration for this retrospective study was between October 2003 and December 2014. The records of total 87 patients with early-stage glottic carcinoma who have been treated with hypofractionated RT were identified through the head and neck database as well as the online information system. Hypofractionated RT was defined as the delivery of a smaller total RT dose in few larger fractions. All patients were included in the study. $94 \%$ of the patients were male and $6 \%$ were female. $78 \%$ belonged to Punjab while $16 \%$ were from Khyber Pakhtunkhwa Province.

The mean age of the patients was 62 years (range $31-83$ years). $66 \%$ of patients were smokers.

AJCC stage-wise distribution is shown in Table 1 and histologic distribution is shown in Table 2, respectively.
Table 1: AJCC stage distribution

\begin{tabular}{l|c}
\hline AJCC stage & Number of patients (\%) \\
\hline T1a & $66(76)$ \\
\hline T1b & $18(20)$ \\
\hline T2 & $3(4)$ \\
\hline
\end{tabular}

Table 2: Histological subtype distribution

\begin{tabular}{l|c}
\hline Histologic type & Number of patients (\%) \\
\hline Squamous cell carcinoma & $84(97)$ \\
\hline Verrucous carcinoma & $2(2)$ \\
\hline Squamous cell spindle variant & $1(1)$ \\
\hline
\end{tabular}

Median follow-up duration was 59 months with a range of 4-122 months. RT dose was 55 Gy in 20 fractions over a period of 4 weeks. RT was given 5 days a week. $21 \%$ of the patients were treated on cobalt 60 and $79 \%$ of the patients were treated on linear accelerator. Energy used was $6 \mathrm{MV}$ photons. The median RT treatment time was 28 days (range 23-35 days). Patients who lost to follow-up for $<2$ years were contacted through telephone to assess the disease status. OS was defined as the time duration between the start of treatment to the time till death.

\section{Results}

The 10 -year OS as determined by the Kaplan-Meir method was $83 \%$ [Figure 1].

\section{Discussion}

There are certain number of factors that affect the outcome of early glottic cancers which are related to patient, tumour and treatment offered. Females have same prognosis or even better than males in head and neck cancers. The reason for this observation is unknown. In our series, none of the five women failed treatment. Higher T-stage adversely impacted local control. AJCC staging system subclassifies T1 glottis cancers into two types, T1a tumour limited to one vocal cord (may involve anterior or posterior commissure) and $\mathrm{T} 1 \mathrm{~b}$ tumour involvement of both the vocal cords. The incidence of regional nodal metastasis in $\mathrm{T} 1 \mathrm{glottic}$ cancers ranges from $0 \%$ to $2 \%$ while it is $10-15 \%$ in $\mathrm{T} 2$ and T3, respectively. ${ }^{[10,11]}$ Local control rates for T1 


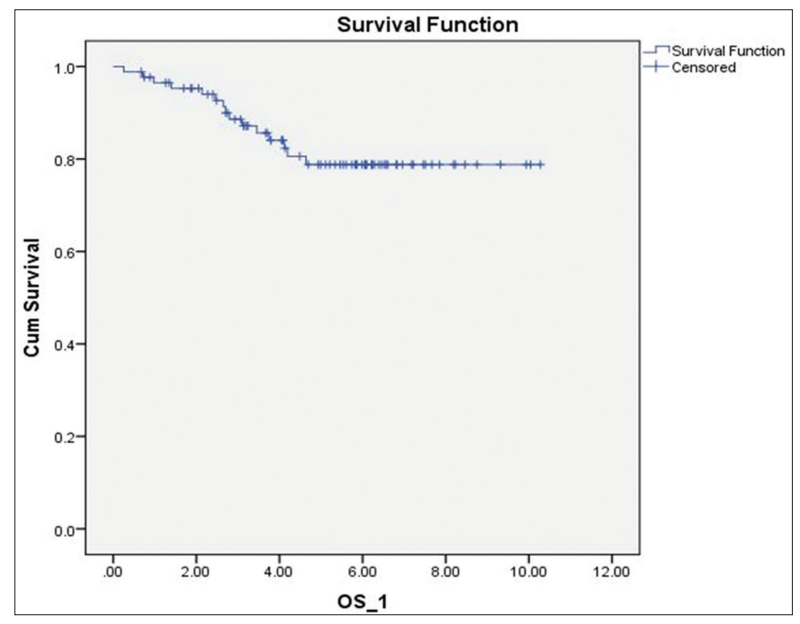

Figure 1: Patterns of failure; local 7, distant 1, while persistent disease in one patient, respectively. 15 patients were dead at the time of study. Cause of death; 13 patients due to ischemic heart disease and two due to primary disease. Voice quality was assessed through telephonic interview with patients having intact larynx. About two-third of the patients were satisfied with their voice quality.

\section{Table 3: Patterns of failure}

\begin{tabular}{l|c}
\hline Patterns of failure & Number of patients (\%) \\
\hline Local & $7(8)$ \\
\hline Distant & $1(1)$ \\
\hline Persistent & $1(1)$ \\
\hline
\end{tabular}

glottis cancer treated with radiation vary between $80 \%$ and $95 \%$ and with surgical salvage ultimate local control rates are between $90 \%$ and $100 \%$. Patients with Stage T1b lesions are considered to have a lower local control rates compared with T1a tumours. ${ }^{[12,14,15]}$ In a series covering 449 patients, local control rates for T1 a and T1b were 91\% and $82 \%$, respectively. ${ }^{[12]}$ However, other authors have failed to show such difference in locoregional control (LRC) for T1 lesions. ${ }^{[5-9]}$ The management plans for T2 carcinoma of the glottis cancers remain controversial and have wide variations. In general, T2 lesions have poor cure rates than $\mathrm{T} 1$ lesions. The local control rates for T2 squamous cell carcinoma of the glottis with conventional RT are approximately $71-85 \%$ and salvage rate for local radiation failure is $88-95 \%$. ${ }^{[7]}$ In our study, a total number of patients with T2 tumour were four. They were treated with conventional fractionation encompassing the primary site and upper neck with radiation treatment portals. Among the four patients with T2 tumours, two had local failure at 9 and 14 months following treatment that was salvaged with laryngectomy [Table 3].

Anterior commissure involvement has been reported by some authors to be associated with poor local control; however, it is controversial. A review of approximately 2200 Stage I patients with glottic carcinoma showed no increase in local failure with anterior commissure involvement. ${ }^{[16,17]}$ Other studies indicate that anterior commissure involvement is a poor prognostic variable for local control with both RT and surgery. ${ }^{[4-9]}$

Other factors associated with poor outcome in early glottic cancers include total dose ( $<65 \mathrm{~Gy}),{ }^{[18,19]}$ overall treatment time ( $>41$ days), poorly differentiated histology, ${ }^{[20]}$ smaller fraction sizes ( $<2$ Gy vs. $>2$ Gy), ${ }^{[21]}$ subglottic extension, treatment delay ( $>3$ days), ${ }^{[22]}$ treatment interruptions, age and smaller field size. ${ }^{[22]}$ Smokers, particularly those who continue to smoke after treatment, are considered to have a worse LRC. ${ }^{[10]}$

The potential risk of prolonged overall RT treatment time in head and neck cancer is well documented. Prolonged overall RT treatment time has a negative impact on LRC and survival. ${ }^{[23]}$ Rudoltz et al. reported $100 \%$ local control when RT was completed within 42 days, in contrast to $50 \%$ local control when treatment lasted from 55 to 66 days. ${ }^{[24]}$

Fein et al. in his study reported a lower local control rate when radiation was extended for $<50$ days in the management of T1-T2 glottic carcinoma. ${ }^{[16]}$ Machine breakdown, holidays and patient-related factors are major causes for treatment interruptions. An audit by Royal College of Radiologists of radical RT for head and neck cancer showed that $81 \%$ of treatment interruptions were due to machine breakdown or servicing. ${ }^{[25]}$ Local control rate may be affected by size of the fraction. Many studies have demonstrated better local control rates if fraction size is $\geq 2$ Gy. ${ }^{[26-30]}$ Short et al. reported 95\% LRC with accelerated hypofractionated regimen 52.5-55 Gy over the period of 4 weeks compared with $75 \%$ when treating with 60-66 Gy over the period of 6-6.5 weeks $(P=0.002) .{ }^{[26]}$ In another study covering 171 patients, control rate was significantly improved using 2 Gy than $1.8 \mathrm{~Gy} /$ fraction. ${ }^{[27]}$ Patients treated with higher fraction size $>3$ Gy have a higher risk of developing late complications, and this is in contrast to the findings of the British Institute of Radiology 
(BIR) trial. ${ }^{[10,29,30]}$ In our study, only 7 of 87 patients $(8 \%)$ failed locally which account for $82 \%$ local control rate that is in contrast with published international literature.

The optimum beam energy advocated for the management of early glottic carcinoma is cobalt-60 or $4 \mathrm{MV}$ photons. ${ }^{[17]}$ The rationale for using lower beam energy is the fact that high-energy photons have increased penetrating power that causes inadequate build-up in the anterior commissure due to thin wedge shape of the midline of the neck that lead to underdose of tumour. Dosimetry studies to calculate the degree of underdosage have yielded conflicting results. The dose absorbed in the anterior commissure decreased by $12 \%$ with $6 \mathrm{MV}$ photons and $18 \%$ with $10 \mathrm{MV}$ photons when compared with cobalt-60. ${ }^{[31]}$ Akaine et al. reported on 154 patients with Stage T1 tumours treated with $6 \mathrm{MV}$; the 5-year local control rate with and without anterior commissure involvement was 81\% (27 patients) and 91\% (127 patients), respectively. While the result did not reach statistical significance, it does invoke clinical concern. ${ }^{[32]}$ Conversely, data from other retrospective studies suggest that the estimated 5-year local control rates with 6,8 and $10 \mathrm{MV}$ photons may be similar to those achieved with cobalt-60. ${ }^{[28]}$

Various studies have indicated that endoscopic laser excision produces oncologic outcome and voice quality comparable to RT treatment. ${ }^{[33]}$ While radiation is often favoured as it appears to be associated with reduced impairment of voice quality, but qualitative studies about vocal function in post-irradiated patients have been inconclusive and not uniform. ${ }^{[34-36]}$ Dinapoli et al. reported on 143 patients with T1 glottis cancer; 73 underwent surgery and 70 underwent RT. No statistically significant differences were found between the two groups in terms of OS and disease-free survival, and better scores for voice quality were found for patients receiving RT compared to surgery. ${ }^{[37,38]}$ In our study, there was no formal assessment of voice. Telephonic interview was done with patients having intact larynx. About two-third of the patients were satisfied with their voice quality.

There are several limitations for this study. First, our study is a single institutional retrospective review spanning over one decade. The second limitation includes availability of only subjective measurement of patient and physician-reported voice quality measures. Finally, as all of our patients received treatment with two-dimensional planning system, tumour volume and tumour volume dosimetry are better captured in modern three-dimensional treatment techniques.

\section{Conclusion}

Hypofractionated RT 55 Gy in 20 fractions seems to achieve good OS for T1-T2 N0 glottis squamous cell carcinoma with good voice preservation.

\section{Conflict of Interest}

The authors declare that they have no conflict of interest.

\section{References}

1. Ferlay J, Bray F, Pisani P, et al. Globocan 2000: Cancer Incidence, Mortality and Prevalence Worldwide. Version 1. Cancer Base No. 5. Lyon: IARC Press; 2001.

2. Myers EN, Suen JY, Myers JN, Hanna E0. Cancer of the Head and Neck. $4^{\text {th }}$ ed. Philadelphia, PA: Saunders; 2003.

3. Million RR, Cassisi NJ, Mancuso AA. Larynx. In: Million RR, cassisi NJ, editors. Management of head and neck cancer, a multidisciplinary approach. $2^{\text {nd }}$ ed. Philadelphia, PA: JB Lippincott; 1994. p. 431-97.

4. Kaiser TN, Spector GJ. Tumors of the larynx and laryngopharynx. In: Ballanger JJ, editor. Diseases of the Nose, Throat, Ear, Head and Neck. $14^{\text {th }}$ ed. Philadelphia, PA: Lea and Febiger; 1991. p. 682-746.

5. Mendenhall WM, Amdur RJ, Morris CG, et al. T1-T2N0 squamous cell carcinoma of the glottic larynx treated with radiation therapy. J Clin Oncol 2001;19:4029-36.

6. American Society of Clinical Oncology, Pfister DG, Laurie SA, et al. American society of clinical oncology clinical practice guideline for the use of larynx-preservation strategies in the treatment of laryngeal cancer. J Clin Oncol 2006;24:3693-704.

7. Mendenhall WM, Parsons JT, Million RR, et al. T1-T2 squamous cell carcinoma of the glottic larynx treated with radiation therapy: Relationship of dose-fractionation factors to local control and complications. Int J Radiat Oncol Biol Phys 1988; 15:1267-73.

8. Mendenhall WM, Parsons JT, Stringer SP, et al. Management of tis, T1, and T2 squamous cell carcinoma of the glottic larynx. Am J Otolaryngol 1994;15:250-7.

9. Williams MV, James ND, Summers ET, et al. National survey of radiotherapy fractionation practice in 2003. Clin Oncol (R Coll Radiol) 2006;18:3-14.

10. van der Voet JC, Keus RB, Hart AA, et al. The impact of treatment time and smoking on local control and complications in T1 glottic cancer. Int J Radiat Oncol Biol Phys 1998;42:247-55.

11. Wang CC. Radiation Therapy for Head and Neck 
Neoplasms. $2^{\text {nd }}$ ed. Washington DC: Year Book Medical Publishers, Inc.; 1990. p. 228-9.

12. Warde P, O'Sullivan B, Bristow RG, et al. T1/T2 glottic cancer managed by external beam radiotherapy: The influence of pretreatment hemoglobin on local control. Int J Radiat Oncol Biol Phys 1998;41:347-53.

13. Jamshed A, Hussain R, Hameed S, et al. Hypopfractionated radiotherapy in the treatment of early glottic carcinoma. 2011. DOI: $10.5005 /$ jp-journals-10001-1069.

14. Epstein BE, Lee DJ, Kashima H, et al. Stage T1 glottic carcinoma: Results of radiation therapy or laser excision. Radiology 1990;175:567-70.

15. Cellai E, Chiavacci A, Olmi P. Causes of failure of curative radiation therapy in 205 early glottic cancers. Int J Radiat Oncol Biol Phys 1990;19:1139-42.

16. Fein DA, Lee WR, Hanlon AL, et al. Do overall treatment time, field size, and treatment energy influence local control of T1-T2 squamous cell carcinomas of the glottic larynx? Int J Radiat Oncol Biol Phys 1996;34:823-31.

17. Million RR. The larynx. So to speak: Everything I wanted to know about laryngeal cancer I learned in the last 32 years. Int J Radiat Oncol Biol Phys 1992;23:691-704.

18. Sessions DG, Ogura JH, Fried MP. The anterior commissure in glottic carcinoma. Laryngoscope 1975;85:1624-32.

19. Le QT, Fu KK, Kroll S, et al. Influence of fraction size, total dose, and overall time on local control of T1-T2 glottic carcinoma. Int J Radiat Oncol Biol Phys 1997;39:115-26.

20. Chera BS, Amdur RJ, Morris CG, et al. T1N0 to T2N0 squamous cell carcinoma of the glottic larynx treated with definitive radiotherapy. Int J Radiat Oncol Biol Phys 2010;78:461-6.

21. Garden AS, Forster K, Wong PF, et al. Results of radiotherapy for T2N0 glottic carcinoma: Does the " 2 " stand for twice-daily treatment? Int J Radiat Oncol Biol Phys 2003;55:322-8.

22. Groome PA, O'Sullivan B, Mackillop WJ, et al. Compromised local control due to treatment interruptions and late treatment breaks in early glottic cancer: Populationbased outcomes study supporting need for intensified treatment schedules. Int J Radiat Oncol Biol Phys 2006;64:1002-12.

23. Overgaard J, Alsner J, Eriksen J, et al. Importance of overall treatment time for the response to radiotherapy in patients with squamous cell carcinoma of the head and neck. Rays 2000;25:313-9.

24. Rudoltz MS, Benammar A, Mohiuddin M. Prognostic factors for local control and survival in T1 squamous cell carcinoma of the glottis. Int J Radiat Oncol Biol Phys 1993;26:767-72.
25. James ND, Robertson G, Squire CJ, et al. A national audit of radiotherapy in head and neck cancer. Clin Oncol (R Coll Radiol) 2003;15:41-6.

26. Short S, Krawitz H, Macannn A, et al. T1N0/T2N0 glottic carcinoma: A comparision of two fractionation schedules. Australas Radiol 2006;50:152-157.

27. Kim RY, Marks ME, Salter MM. Early-stage glottic cancer: Importance of dose fractionation in radiation therapy. Radiology 1992;182:273-5.

28. Ricciardelli EJ, Weymuller EA Jr., Koh WJ, et al. Effect of radiation fraction size on local control rates for early glottic carcinoma. A model analysis for in vivo tumor growth and radio-response parameters. Arch Otolaryngol Head Neck Surg 1994;120:737-42.

29. Small W Jr., Mittal BB, Brand WN, et al. Results of radiation therapy in early glottic carcinoma: Multivariate analysis of prognostic and radiation therapy variables. Radiology 1992;183:789-94.

30. Wiernik G, Alcock CJ, Bates TD, et al. Final report on the second British institute of radiology fractionation study: Short versus long overall treatment times for radiotherapy of carcinoma of the laryngo-pharynx. Br J Radiol 1991;64:232-41.

31. Shimizu R. An evaluation of absorbed doses of high energy electromagnetic radiation in radiotherapy of laryngeal cancer. Nihon Jibiinkoka Gakkai Kaiho 1990;93:796-807.

32. Akine Y, Tokita N, Ogino T, et al. Radiotherapy of T1 glottic cancer with $6 \mathrm{MeV}$ x rays. Int J Radiat Oncol Biol Phys 1993;26:767-72.

33. Foote RL, Grado GL, Buskirk SJ, et al. Radiation therapy for glottic cancer using 6-MV photons. Cancer 1996;77:381-6.

34. Steiner W. Results of curative laser microsurgery of laryngeal carcinomas. Am J Otolaryngol 1993;14:116-21.

35. Spector JG, Sessions DG, Chao KS, et al. Stage I (T1 N0 M0) squamous cell carcinoma of the laryngeal glottis: Therapeutic results and voice preservation. Head Neck 1999;21:707-17.

36. Ambrosch $\mathrm{P}$. The role of laser microsurgery in the treatment of laryngeal cancer. Curr Opin Otolaryngol Head Neck Surg 2007;15:82-8.

37. Cohen SM, Garrett CG, Dupont WD, et al. Voicerelated quality of life in T1 glottic cancer: Irradiation versus endoscopic excision. Ann Otol Rhinol Laryngol 2006;115:581-6.

38. Dinapoli N, Parrilla C, Galli J, et al. Multidisciplinary approach in the treatment of $\mathrm{T} 1$ glottic cancer. The role of patient preference in a homogenous patient population. Strahlenther Onkol 2010;186:607-13. 